\title{
DYSTROPHIC CHANGES ASSOCIATED WITH LEPRECHAUNISM IN A MALE INFANT
}

\author{
BY \\ M. A. SALMON* and J. N. WEBB \\ From Southampton Children's Hospital and the Department of Pathology, \\ Royal Hampshire County Hospital, Winchester
}

(RECEIVED FOR PUBLICATION APRIL 4, 1963)

\begin{abstract}
'The first things they became aware of were six small men seated on low roots. They were dressed in tight green clothes and little leathern aprons. They were busily engaged in making shoes.'
\end{abstract}

This account by James Stephens (1912) of no less than six male leprechauns seen simultaneously has not been improved upon, for the medical literature to date includes descriptive accounts of only five examples of the rare syndrome of leprechaunism, and only one of these is male.

Leprechaunism was first described by Donohue (1948) and later by Donohue and Uchida (1954), Evans (1955), Schaffer (1960) and Patterson and Watkins (1962). It is not a well-defined syndrome and a number of patients with some of the features of leprechaunism have been described under other names by Hall, Sunderman and Gittings (1936), Murray (1952), Berardinelli (1954), Schwartz, Schafer and Renold (1960), Senior (1961), Hitzig and Willi (1961) and Freycon, Jeune, Larbre and Germain (1961). Although these cases are not examples of leprechaunism their importance in the differential diagnosis of the condition will be discussed later.

The following account is only the second record of a male infant with leprechaunism.

\section{Case Report}

D.M. was the second child of consanguineous parents, the mother being unmarried. The pregnancy was uncomplicated by drugs or illness and terminated spontaneously at 34 weeks. The birth weight was $1.78 \mathrm{~kg}$. The mother had two previous pregnancies by fathers who, apart from being brothers, were also consanguineous with her. At birth the baby's condition was satisfactory, but at 24 hours some head retraction and spasticity were noticed. There were occasional myoclonic movements. Feeding was very difficult as he appeared disinterested and most early feeds were given by oesophageal tube.

* Present address: University College Hospital, Ibadan, Nigeria.
From the age of 1 week a bilateral basal pneumonia developed and this recurred throughout the baby's life. It was associated with a persistent nasal discharge, coughing and cyanotic attacks. Weight gain was very slow and averaged from 20-90 g. each week until the last six weeks of life when there was some weight loss. After spending the first five months of life in hospital he was sent home only to appear in out-patients three weeks later, in wretched condition and barely $30 \mathrm{~g}$. heavier than on discharge. He was readmitted and died suddenly at 7 months of age. His weight at death was $3.35 \mathrm{~kg}$.

The facies was that characteristic of leprechaunism (Fig. 1). The ears were very large and low set, and a fine growth of hair covered the forehead and extended to the angles of the jaw. The head was very small, its circumference at birth being $27 \cdot 25 \mathrm{~cm}$. and at 7 months only $31.0 \mathrm{~cm}$. The posterior fontanelle was widely open at birth but both this and the anterior fontanelle were closed by 3 months. The body was thin and dystrophic and the hands and feet were large. The Moro and grasp reflexes were present. There was no abnormal development of the breasts or genitalia and the testicles remained undescended at 7 months.

Investigations. The blood picture was investigated several times throughout the baby's life and was unremarkable. The white cell count varied from $8,900 / \mathrm{c} . \mathrm{mm}$. to $23,000 / \mathrm{c} . \mathrm{mm}$. with a high proportion of lymphocytes (varying from $63-86 \%$ ).

$\mathrm{X}$-ray examination showed that there was considerable delay in ossification and the bone age at 7 months was that of an infant of 3 months. The skull radiographs showed a microcephalic vault with parietal foramina. The sella turcica was normal.

Electrocardiography revealed no abnormality.

The following investigations of blood biochemistry were within normal limits: urea, total amino acid nitrogen, creatine, creatinine, sodium, potassium, chloride, inorganic phosphate, liver function tests and Sabin-Feldman dye test for toxoplasmosis. Unusual findings were as follows:

(a) Serum cholesterol: this was very low and appeared to decrease with age, being $135 \mathrm{mg} . / 100 \mathrm{ml}$. at 3 months and only $53 \mathrm{mg} . / 100 \mathrm{ml}$. at 7 months. 


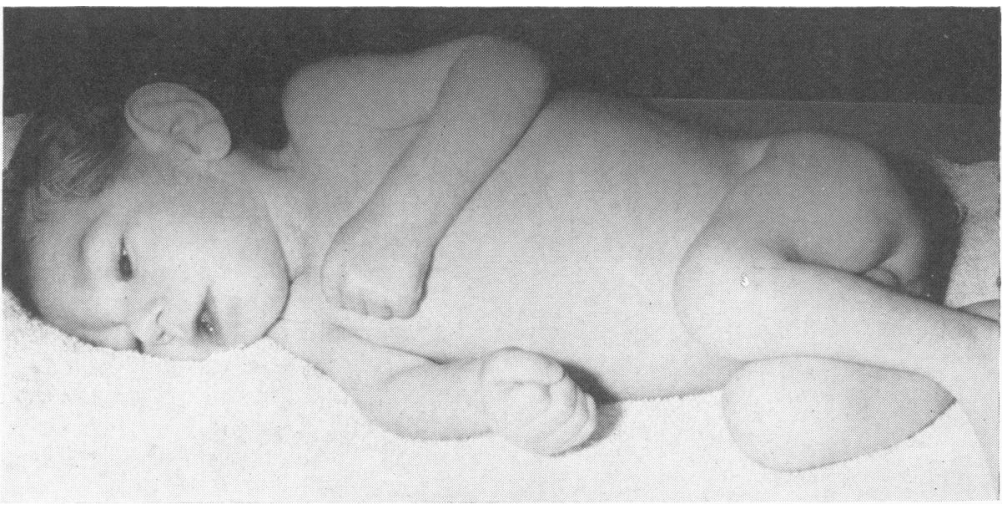

FIG. 1.-Showing the appearance of the child.

(b) Alkaline phosphatase: this also appeared to decrease with age, being 24.0 King-Armstrong units at 3 months, $11.0 \mathrm{~K}$.-A. units at 6 months and $8.0 \mathrm{~K}$.-A. units at 7 months.

(c) Plasma proteins: these were essentially normal except for an increase in the $\alpha_{2}$ fraction $(1.05 \mathrm{~g}$. $/ 100 \mathrm{ml}$.) of the globulins.

The results of the following urine investigations revealed no abnormalities: sugar, blood, protein, phenylpyruvic acid, creatine, creatinine, sodium, potassium, 17-ketosteroids, 17-corticosteroids, cytomegalic inclusion bodies. Chromatography showed a normal pattern at 3 months but at 6 months revealed a diffuse aminoaciduria. The normal pattern was grossly exaggerated and in addition there were quantities of cystine, isoleucine, aspartic acid, threonine, p-aminoisobutyric acid, phenylalanine and ethanolamine.

The cerebrospinal fluid was examined on two occasions and found to be normal.

Microscopy of the faeces revealed no disease and tests for tryptic activity were normal. There was an increased fat excretion with an average daily output of $4.6 \mathrm{~g}$.

\section{Tests of Carbohydrate Metabolism}

(a) Glucose tolerance test: the fasting blood sugar was low on several occasions and oral glucose produced a very flat curve when compared with a normal control. There was a maximum rise in blood sugar of only $10 \mathrm{mg} . / 100 \mathrm{ml}$. (Fig. 2).

(b) Insulin tolerance test: a characteristic of the cases described by Evans (1955) was a prolonged response to insulin. Insulin tolerance tests were performed on this infant using a normal 6-month-old baby as control. As it was thought that the failure of growth might be a manifestation of hypopituitarism only one-third of the standard amount of insulin $(0 \cdot 25$ units $/ \mathrm{kg}$.) was used. It will be seen that in this case there was also a prolonged response to insulin with a slow drop in blood sugar from a fasting level of $62 \mathrm{mg} . / 100 \mathrm{ml}$. to $42 \mathrm{mg} . / 100 \mathrm{ml}$. at two hours (Fig. 2).

(c) Adrenaline (epinephrine) test: at the conclusion of the insulin tolerance test adrenaline was given subcutaneously $(0.03 \mathrm{ml} . / \mathrm{kg}$. $)$ to determine the availability of liver glycogen. In this case there was a very limited response and even after three hours the blood sugar had not risen to its fasting level (Fig. 2).

Autopsy. This was carried out by one of us (J.N.W.). The body was that of an emaciated male infant weighing $3.35 \mathrm{~kg}$. The head circumference was $31 \mathrm{~cm}$., the heel to crown measurement was $57 \mathrm{~cm}$. and the rump to crown measurement $36 \mathrm{~cm}$. There was very little subcutaneous fat and the body was covered with fine downy hair, which was most pronounced over the forehead. Both the testicles were undescended and the penis was prominent.

The anterior fontanelle was closed; the brain weighed $180 \mathrm{~g}$. (normal $430 \mathrm{~g}$.). There was an extreme degree of internal hydrocephalus, each hemisphere consisting of a sac filled with cerebrospinal fluid. The brain-stem

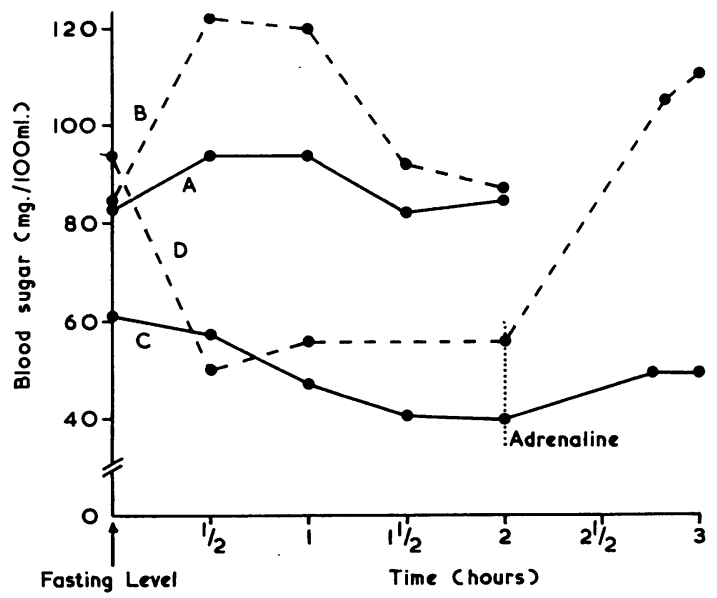

FIG. 2.-A-Glucose tolerance curve; $\mathrm{B}$-from control; $\mathrm{C}$-insulin tolerance curve with adrenaline test; D-from control. 


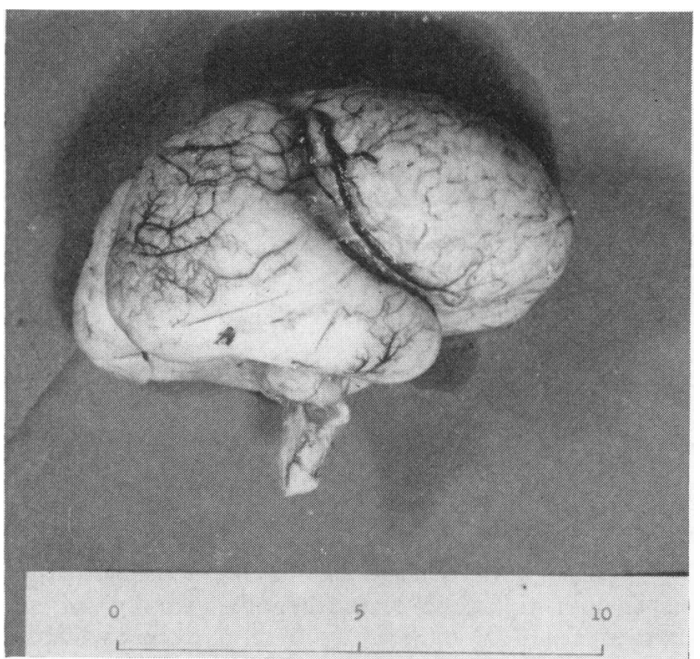

Fig. 3.-Brain, to show agyria and hypogenesis of the cerebellum.

appeared normal and there was a rudimentary cerebellum. The cerebral hemispheres showed complete agyria (Fig. 3).

The thymus was atrophic, weighing less than $3 \mathrm{~g}$. (normal $10 \mathrm{~g}$.). The thyroid was less than $2 \mathrm{~g}$. (normal $2.4 \mathrm{~g}$.) and the parathyroids could not be seen with the naked eye. The pituitary, adrenals and testicles appeared normal. The spleen weighed $10 \mathrm{~g}$. (normal
11-12 g.) and was pale. The lymph nodes were inconspicuous except for one infratracheal node which was enlarged, soft and congested. The pancreas looked normal but was greatly enlarged (15 g. as compared with a normal 3.6 g.). The liver had a mottled appearance and weighed $250 \mathrm{~g}$. (normal $150 \mathrm{~g}$.). The gall-bladder and extrahepatic biliary tree were normal. The combined weight of the kidneys was $32 \mathrm{~g}$. (normal $26 \mathrm{~g}$.). There were no foetal lobulations. There was no abnormality of the cardiovascular or alimentary systems.

There was a small quantity of inhaled milk and frothy mucus in the trachea and bronchi. In addition there was consolidation due to pneumonia in the right upper, middle and lower lobes with an overlying fibrinous pleurisy. There was pneumonic consolidation of the left lower lobe.

Death was due to pneumonia associated with a generalized wasting condition and retarded growth.

Histological Examination. The thyroid, parathyroids, adrenals, myocardium and epiphyses revealed no disease. The essential histological findings were as follows:

(a) The liver showed some passive venous congestion with degeneration of the liver cells in the congested areas. It was stained specifically for iron and glycogen, both of which were absent.

(b) The kidneys contained unduly dilated tubules (Fig. 4), some of which were filled with amorphous, eosinophilic debris.

(c) The thymus was atrophic and contained numerous large cystic spaces together with scanty lymphoid tissue (Fig. 5). The lymphoid tissue of the spleen was particularly sparse, and atrophic lymphoid tissue was a

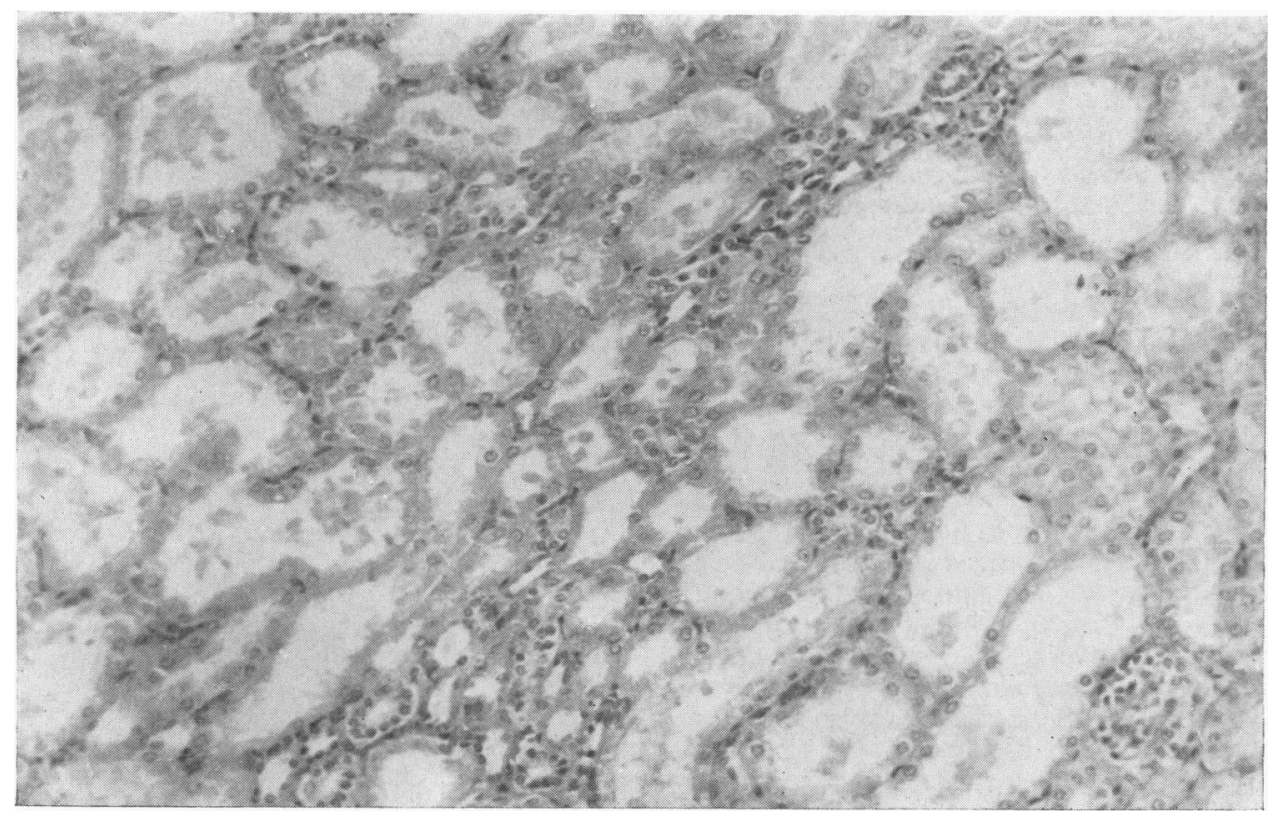

FIG. 4.-Kidney $(\times 90)$ to show dilated tubules filled with eosinophilic debris. 


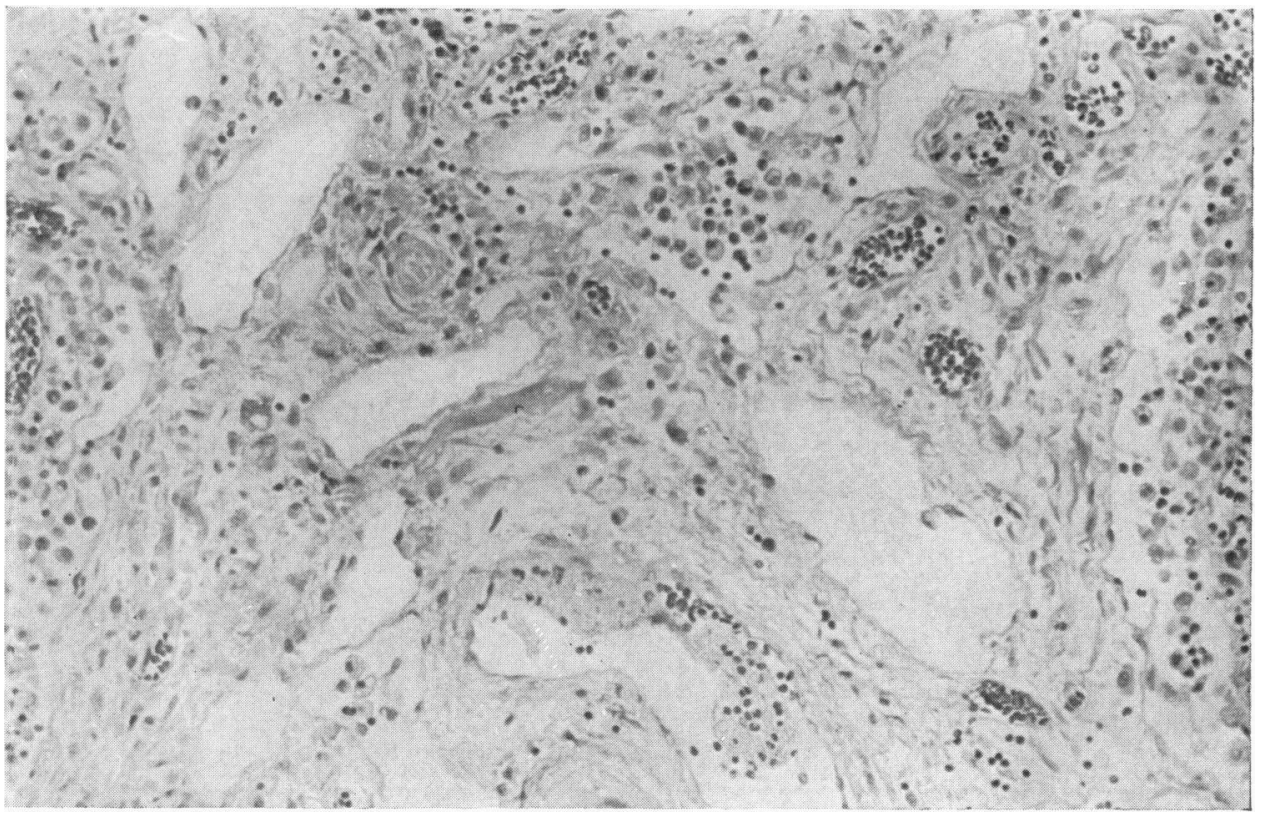

Fig. 5.-Thymus $(\times 90)$ to show cystic structure.

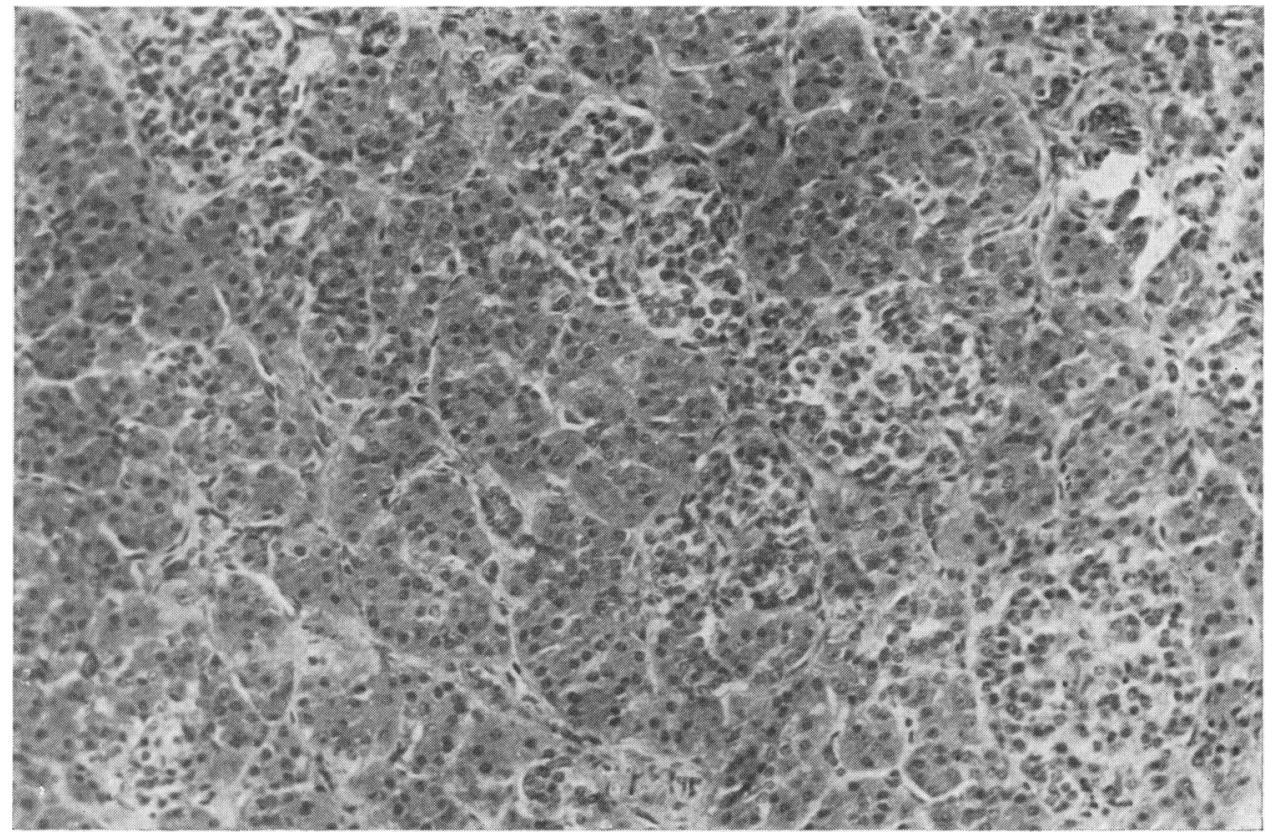

FIG. 6.-Pancreas $(\times 90)$ to show islet cell hyperplasia. 
TABLE

COMPARISON OF SIX CASES OF LEPRECHAUNISM

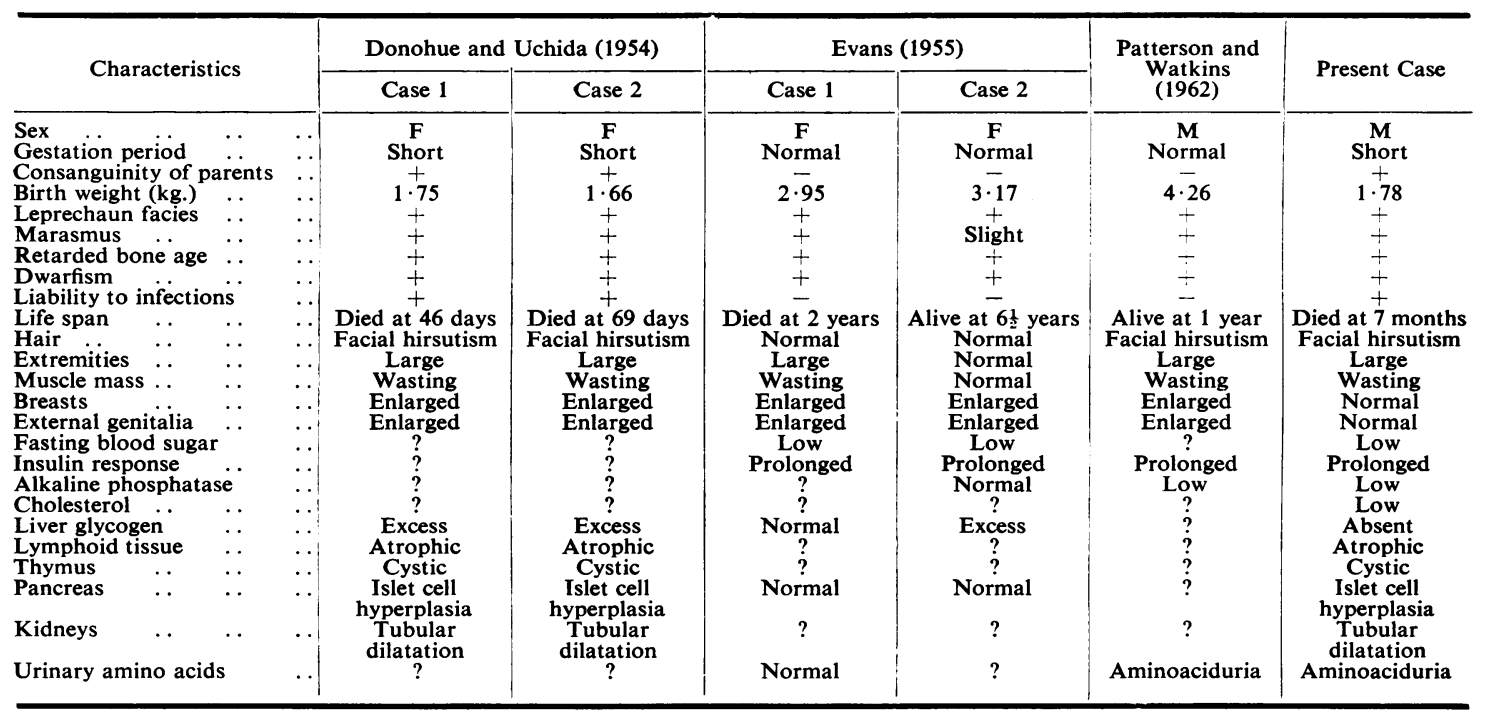

feature of the one lymph node examined. This node was draining an area of bronchopneumonia and although the sinuses were filled with macrophages and plasma cells the lymph follicles were scanty and with no obvious germinal centres.

(d) In the pancreas was a superabundance of groups of islet cells, but otherwise there was no abnormality (Fig. 6).

(e) The pituitary showed a complete absence of $\mathrm{S}$ basophil cells in the adenohypophysis, but acidophils, chromophobes and $\mathrm{R}$ cells were present.

\section{Discussion}

In discussing the characteristic features of leprechaunism we are limited by the small number of cases so far described. The two cases of Donohue and Uchida (1954) were examined extensively after death, but their living pathology was not. This is the converse of the cases seen by Evans (1955) and Patterson and Watkins (1962), who examined their living pathology in detail but, apart from biopsy material, were unable to examine their microscopic anatomy fully.

From the Table it will be seen that certain features are common to all six cases and from this we can draw conclusions enabling us to define the syndrome of leprechaunism. In comparing the cases one notices a tetrad of primary characteristics and a number of secondary findings which may or may not be of importance.

(a) A characteristic facies with enlarged, low-set ears, widely-spaced eyes and facial hirsutism. (b) Dystrophy, with failure of ossification, dwarfism and marasmus.

(c) Atrophy of the lymphoid structures of the body together with cystic degeneration of the thymus and a liability to infection.

(d) Abnormal carbohydrate metabolism, with a low fasting blood sugar, a prolonged response to insulin and extremes of glycogen storage. An endocrine abnormality predisposing to enlargement of the breasts and genitalia.

Other findings which may contribute to the integrity of the syndrome are consanguinity of the parents, a low birth weight and tubular dilatation of the kidneys with an associated aminoaciduria. It is not known whether the exceptionally low serum cholesterol figures in the present case are a feature of this condition. It appears that growth is inhibited, in the most pronounced cases, by one or more factors during the first trimester of life, and the remarkable decrease in serum alkaline phosphatase levels after that time is indicative of a progressive failure of ossification.

It was mentioned earlier that a number of authors have described patients with some of the tabulated characteristics, but which were clearly not examples of leprechaunism. Senior (1961) describes 11 cases of lipodystrophic muscular hypertrophy and includes amongst them the two leprechaun babies of Donohue and Uchida (1954). These bear little resemblance to the other cases listed by him and do not exhibit muscular hypertrophy. More recently Hitzig and 
Willi (1961) and Freycon et al. (1961) have independently described the condition of hereditary lymphoplasmacytic dysgenesia or essential lymphocytothisis. In these cases the affected infants show atrophy of the thymus gland and lymphoid structures and a very low peripheral lymphocyte count. Apart from this the condition cannot be confused with a diagnosis of leprechaunism. It is possible that as more cases are described the identity of a leprechaun may become more distinct and a group of related disorders better recognized.

\section{Summary}

The rare syndrome of leprechaunism is known from only five examples, four of whom were female. A second male infant with the same characteristics is now described and the six cases compared so as to define the syndrome more accurately than was previously possible.
Our thanks are due to Dr. G. Ormiston for permission to publish this case and to Drs. D. A. J. Williamson, R. L. V. Pearce, C. S. Shaw, H. R. G. Richards and D. Kennedy for their invaluable help.

\section{Berardinelli, W. (1954) REFERENCES}

An undiagnosed endoc syndrome: Report of 2 cases. J. clin. Endocr., 14, 193.

Donohue, W. L. (1948). Clinicopathologic conference at the Hospital for Sick Children, Toronto. Dysendocrinism. J. Pediat., 32, 739.

- and Uchida, I. (1954). Leprechaunism. A euphuism for a rare familial disorder. ibid., 45, 505.

Evans, P. R. (1955). Leprechaunism. Arch. Dis. Childh., 30, 479.

Evans, P. R. (1955). Leprechaunism. Arch. Dis. Childh., 30, 479. lymphocytophtisie essentielle: Aplasie lymphoplasmocytaire du nourrisson avec alymphocytose et hypogammaglobulinémie. Rev. franc. Etud. clin. biol., 6, 817.

Hall, B. E., Sunderman, F. W. and Gittings, J. C. (1936). Congenital muscular hypertrophy. Amer. J. Dis. Child., 52, 773.

Hitzig, W. H. and Willi, H. (1961). Hereditäre lymphoplasmocytäre Dysgenesie. Schweiz. n.ed. Wschr., 91, 1625.

Murray, I. (1952). Lipodystrophy Brit. med.J., 2, 1236.

Murray, 1. (1952). Lipodystrophy. Brit. med. J., 2, 1236 . a male infant. J. Pediat., 60, 730 .

Schaffer. A. J. (1960). Diseases of the Newborn. Saunders, London and Philadelphia.

Schwartz, R., Schafer, I. A. and Renold, A. E. (1960). Generalised lipoatrophy, hepatic cirrhosis, disturbed carbohydrate metabolism and accelerated growth (lipoatrophic diabetes). Amer. J. Med., 28, 973.

Senior, B. (1961). Lipodystrophic muscular hypertrophy. Arch. Dis. Childh 36, 426.

Stephens, J. (1912). The Crock of Gold. Macmillan, London. 